\title{
Oligosaccharides production by enzymatic hydrolysis of banana pseudostem pulp
}

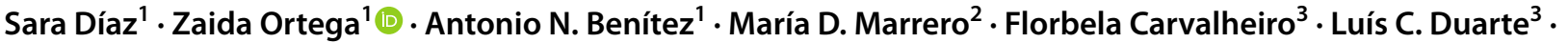 \\ Leonidas Matsakas ${ }^{4}$. Eleni Krikigianni ${ }^{4} \cdot$ Ulrika Rova $^{4} \cdot$ Paul Christakopoulos $^{4} \cdot$ Maria C. Fernandes $^{5,6}$
}

Received: 18 June 2021 / Revised: 25 September 2021 / Accepted: 11 October 2021

(c) The Author(s) 2021

\begin{abstract}
Banana production generates significant amounts of agricultural wastes, being fiber extraction one of the most relevant
alternatives for their valorization. This process produces banana's pseudostem pulp (BPP) as a byproduct, which shows an
interesting composition for the biorefinery's biochemical platform, with high polysaccharides (68\%) and low lignin contents.
This work deals with the enzymatic hydrolysis (EH) of raw and hydrothermally pre-treated BPP, focusing on the production
of oligosaccharides (OS). Raw BPP hydrolysis with cellulase at different dosages rendered only $3.2 \%$ OS yields (OSY).
Pectinase addition has not affected EH performance. On the other hand, EH of hydrothermally pre-treated BPP at $150{ }^{\circ} \mathrm{C}$
and $170{ }^{\circ} \mathrm{C}$ (P150 and P170) allowed to increase OSY up to $28 \%$ (P150, 1 FPU of cellulase/g dry biomass, $12 \mathrm{~h}$ ), being
$72 \%$ of the solubilized sugars in the form of cello-oligosaccharides. This last condition was subjected to a multi-stage EH
strategy without improvements in OSY. An endo-glucanase was also tested, but obtained OSY were lower than cellulase
results. Finally, obtained OS demonstrated to stimulate the growth of two Lactobacilli strains. The results show that BPP
pre-treated under mild operational conditions is a good candidate for cello-oligosaccharides production by EH using $1 \mathrm{FPU} / \mathrm{g}$
Abstract
Banana production generates significant amounts of agricultural wastes, being fiber extraction one of the most relevant
alternatives for their valorization. This process produces banana's pseudostem pulp (BPP) as a byproduct, which shows an
interesting composition for the biorefinery's biochemical platform, with high polysaccharides (68\%) and low lignin contents.
This work deals with the enzymatic hydrolysis (EH) of raw and hydrothermally pre-treated BPP, focusing on the production
of oligosaccharides (OS). Raw BPP hydrolysis with cellulase at different dosages rendered only $3.2 \%$ OS yields (OSY).
Pectinase addition has not affected EH performance. On the other hand, EH of hydrothermally pre-treated BPP at $150{ }^{\circ} \mathrm{C}$
and $170{ }^{\circ} \mathrm{C}(\mathrm{P} 150$ and P170) allowed to increase OSY up to $28 \%$ (P150, 1 FPU of cellulase/g dry biomass, $12 \mathrm{~h}$ ), being
$72 \%$ of the solubilized sugars in the form of cello-oligosaccharides. This last condition was subjected to a multi-stage EH
strategy without improvements in OSY. An endo-glucanase was also tested, but obtained OSY were lower than cellulase
results. Finally, obtained OS demonstrated to stimulate the growth of two Lactobacilli strains. The results show that BPP
pre-treated under mild operational conditions is a good candidate for cello-oligosaccharides production by EH using 1 FPU/g

Abstract
Banana production generates significant amounts of agricultural wastes, being fiber extraction one of the most relevant
alternatives for their valorization. This process produces banana's pseudostem pulp (BPP) as a byproduct, which shows an
interesting composition for the biorefinery's biochemical platform, with high polysaccharides (68\%) and low lignin contents.
This work deals with the enzymatic hydrolysis (EH) of raw and hydrothermally pre-treated BPP, focusing on the production
of oligosaccharides (OS). Raw BPP hydrolysis with cellulase at different dosages rendered only $3.2 \%$ OS yields (OSY).
Pectinase addition has not affected EH performance. On the other hand, EH of hydrothermally pre-treated BPP at $150{ }^{\circ} \mathrm{C}$
and $170{ }^{\circ} \mathrm{C}(\mathrm{P} 150$ and P170) allowed to increase OSY up to $28 \%$ (P150, 1 FPU of cellulase/g dry biomass, $12 \mathrm{~h}$ ), being
$72 \%$ of the solubilized sugars in the form of cello-oligosaccharides. This last condition was subjected to a multi-stage EH
strategy without improvements in OSY. An endo-glucanase was also tested, but obtained OSY were lower than cellulase
results. Finally, obtained OS demonstrated to stimulate the growth of two Lactobacilli strains. The results show that BPP
pre-treated under mild operational conditions is a good candidate for cello-oligosaccharides production by EH using 1 FPU/g

Abstract
Banana production generates significant amounts of agricultural wastes, being fiber extraction one of the most relevant
alternatives for their valorization. This process produces banana's pseudostem pulp (BPP) as a byproduct, which shows an
interesting composition for the biorefinery's biochemical platform, with high polysaccharides (68\%) and low lignin contents.
This work deals with the enzymatic hydrolysis (EH) of raw and hydrothermally pre-treated BPP, focusing on the production
of oligosaccharides (OS). Raw BPP hydrolysis with cellulase at different dosages rendered only $3.2 \%$ OS yields (OSY).
Pectinase addition has not affected EH performance. On the other hand, EH of hydrothermally pre-treated BPP at $150{ }^{\circ} \mathrm{C}$
and $170{ }^{\circ} \mathrm{C}(\mathrm{P} 150$ and P170) allowed to increase OSY up to $28 \%$ (P150, 1 FPU of cellulase/g dry biomass, $12 \mathrm{~h}$ ), being
$72 \%$ of the solubilized sugars in the form of cello-oligosaccharides. This last condition was subjected to a multi-stage EH
strategy without improvements in OSY. An endo-glucanase was also tested, but obtained OSY were lower than cellulase
results. Finally, obtained OS demonstrated to stimulate the growth of two Lactobacilli strains. The results show that BPP
pre-treated under mild operational conditions is a good candidate for cello-oligosaccharides production by EH using 1 FPU/g

Abstract
Banana production generates significant amounts of agricultural wastes, being fiber extraction one of the most relevant
alternatives for their valorization. This process produces banana's pseudostem pulp (BPP) as a byproduct, which shows an
interesting composition for the biorefinery's biochemical platform, with high polysaccharides (68\%) and low lignin contents.
This work deals with the enzymatic hydrolysis (EH) of raw and hydrothermally pre-treated BPP, focusing on the production
of oligosaccharides (OS). Raw BPP hydrolysis with cellulase at different dosages rendered only $3.2 \%$ OS yields (OSY).
Pectinase addition has not affected EH performance. On the other hand, EH of hydrothermally pre-treated BPP at $150{ }^{\circ} \mathrm{C}$
and $170{ }^{\circ} \mathrm{C}(\mathrm{P} 150$ and P170) allowed to increase OSY up to $28 \%$ (P150, 1 FPU of cellulase/g dry biomass, $12 \mathrm{~h}$ ), being
$72 \%$ of the solubilized sugars in the form of cello-oligosaccharides. This last condition was subjected to a multi-stage EH
strategy without improvements in OSY. An endo-glucanase was also tested, but obtained OSY were lower than cellulase
results. Finally, obtained OS demonstrated to stimulate the growth of two Lactobacilli strains. The results show that BPP
pre-treated under mild operational conditions is a good candidate for cello-oligosaccharides production by EH using 1 FPU/g

Abstract
Banana production generates significant amounts of agricultural wastes, being fiber extraction one of the most relevant
alternatives for their valorization. This process produces banana's pseudostem pulp (BPP) as a byproduct, which shows an
interesting composition for the biorefinery's biochemical platform, with high polysaccharides (68\%) and low lignin contents.
This work deals with the enzymatic hydrolysis (EH) of raw and hydrothermally pre-treated BPP, focusing on the production
of oligosaccharides (OS). Raw BPP hydrolysis with cellulase at different dosages rendered only $3.2 \%$ OS yields (OSY).
Pectinase addition has not affected EH performance. On the other hand, EH of hydrothermally pre-treated BPP at $150{ }^{\circ} \mathrm{C}$
and $170{ }^{\circ} \mathrm{C}(\mathrm{P} 150$ and P170) allowed to increase OSY up to $28 \%$ (P150, 1 FPU of cellulase/g dry biomass, $12 \mathrm{~h}$ ), being
$72 \%$ of the solubilized sugars in the form of cello-oligosaccharides. This last condition was subjected to a multi-stage EH
strategy without improvements in OSY. An endo-glucanase was also tested, but obtained OSY were lower than cellulase
results. Finally, obtained OS demonstrated to stimulate the growth of two Lactobacilli strains. The results show that BPP
pre-treated under mild operational conditions is a good candidate for cello-oligosaccharides production by EH using 1 FPU/g

Abstract
Banana production generates significant amounts of agricultural wastes, being fiber extraction one of the most relevant
alternatives for their valorization. This process produces banana's pseudostem pulp (BPP) as a byproduct, which shows an
interesting composition for the biorefinery's biochemical platform, with high polysaccharides (68\%) and low lignin contents.
This work deals with the enzymatic hydrolysis (EH) of raw and hydrothermally pre-treated BPP, focusing on the production
of oligosaccharides (OS). Raw BPP hydrolysis with cellulase at different dosages rendered only $3.2 \%$ OS yields (OSY).
Pectinase addition has not affected EH performance. On the other hand, EH of hydrothermally pre-treated BPP at $150{ }^{\circ} \mathrm{C}$
and $170{ }^{\circ} \mathrm{C}(\mathrm{P} 150$ and P170) allowed to increase OSY up to $28 \%$ (P150, 1 FPU of cellulase/g dry biomass, $12 \mathrm{~h}$ ), being
$72 \%$ of the solubilized sugars in the form of cello-oligosaccharides. This last condition was subjected to a multi-stage EH
strategy without improvements in OSY. An endo-glucanase was also tested, but obtained OSY were lower than cellulase
results. Finally, obtained OS demonstrated to stimulate the growth of two Lactobacilli strains. The results show that BPP
pre-treated under mild operational conditions is a good candidate for cello-oligosaccharides production by EH using 1 FPU/g

Abstract
Banana production generates significant amounts of agricultural wastes, being fiber extraction one of the most relevant
alternatives for their valorization. This process produces banana's pseudostem pulp (BPP) as a byproduct, which shows an
interesting composition for the biorefinery's biochemical platform, with high polysaccharides (68\%) and low lignin contents.
This work deals with the enzymatic hydrolysis (EH) of raw and hydrothermally pre-treated BPP, focusing on the production
of oligosaccharides (OS). Raw BPP hydrolysis with cellulase at different dosages rendered only $3.2 \%$ OS yields (OSY).
Pectinase addition has not affected EH performance. On the other hand, EH of hydrothermally pre-treated BPP at $150{ }^{\circ} \mathrm{C}$
and $170{ }^{\circ} \mathrm{C}(\mathrm{P} 150$ and P170) allowed to increase OSY up to $28 \%$ (P150, 1 FPU of cellulase/g dry biomass, $12 \mathrm{~h}$ ), being
$72 \%$ of the solubilized sugars in the form of cello-oligosaccharides. This last condition was subjected to a multi-stage EH
strategy without improvements in OSY. An endo-glucanase was also tested, but obtained OSY were lower than cellulase
results. Finally, obtained OS demonstrated to stimulate the growth of two Lactobacilli strains. The results show that BPP
pre-treated under mild operational conditions is a good candidate for cello-oligosaccharides production by EH using 1 FPU/g

Abstract
Banana production generates significant amounts of agricultural wastes, being fiber extraction one of the most relevant
alternatives for their valorization. This process produces banana's pseudostem pulp (BPP) as a byproduct, which shows an
interesting composition for the biorefinery's biochemical platform, with high polysaccharides (68\%) and low lignin contents.
This work deals with the enzymatic hydrolysis (EH) of raw and hydrothermally pre-treated BPP, focusing on the production
of oligosaccharides (OS). Raw BPP hydrolysis with cellulase at different dosages rendered only $3.2 \%$ OS yields (OSY).
Pectinase addition has not affected EH performance. On the other hand, EH of hydrothermally pre-treated BPP at $150{ }^{\circ} \mathrm{C}$
and $170{ }^{\circ} \mathrm{C}(\mathrm{P} 150$ and P170) allowed to increase OSY up to $28 \%$ (P150, 1 FPU of cellulase/g dry biomass, $12 \mathrm{~h}$ ), being
$72 \%$ of the solubilized sugars in the form of cello-oligosaccharides. This last condition was subjected to a multi-stage EH
strategy without improvements in OSY. An endo-glucanase was also tested, but obtained OSY were lower than cellulase
results. Finally, obtained OS demonstrated to stimulate the growth of two Lactobacilli strains. The results show that BPP
pre-treated under mild operational conditions is a good candidate for cello-oligosaccharides production by EH using 1 FPU/g

Abstract
Banana production generates significant amounts of agricultural wastes, being fiber extraction one of the most relevant
alternatives for their valorization. This process produces banana's pseudostem pulp (BPP) as a byproduct, which shows an
interesting composition for the biorefinery's biochemical platform, with high polysaccharides (68\%) and low lignin contents.
This work deals with the enzymatic hydrolysis (EH) of raw and hydrothermally pre-treated BPP, focusing on the production
of oligosaccharides (OS). Raw BPP hydrolysis with cellulase at different dosages rendered only $3.2 \%$ OS yields (OSY).
Pectinase addition has not affected EH performance. On the other hand, EH of hydrothermally pre-treated BPP at $150{ }^{\circ} \mathrm{C}$
and $170{ }^{\circ} \mathrm{C}(\mathrm{P} 150$ and P170) allowed to increase OSY up to $28 \%$ (P150, 1 FPU of cellulase/g dry biomass, $12 \mathrm{~h}$ ), being
$72 \%$ of the solubilized sugars in the form of cello-oligosaccharides. This last condition was subjected to a multi-stage EH
strategy without improvements in OSY. An endo-glucanase was also tested, but obtained OSY were lower than cellulase
results. Finally, obtained OS demonstrated to stimulate the growth of two Lactobacilli strains. The results show that BPP
pre-treated under mild operational conditions is a good candidate for cello-oligosaccharides production by EH using 1 FPU/g

Abstract
Banana production generates significant amounts of agricultural wastes, being fiber extraction one of the most relevant
alternatives for their valorization. This process produces banana's pseudostem pulp (BPP) as a byproduct, which shows an
interesting composition for the biorefinery's biochemical platform, with high polysaccharides (68\%) and low lignin contents.
This work deals with the enzymatic hydrolysis (EH) of raw and hydrothermally pre-treated BPP, focusing on the production
of oligosaccharides (OS). Raw BPP hydrolysis with cellulase at different dosages rendered only $3.2 \%$ OS yields (OSY).
Pectinase addition has not affected EH performance. On the other hand, EH of hydrothermally pre-treated BPP at $150{ }^{\circ} \mathrm{C}$
and $170{ }^{\circ} \mathrm{C}(\mathrm{P} 150$ and P170) allowed to increase OSY up to $28 \%$ (P150, 1 FPU of cellulase/g dry biomass, $12 \mathrm{~h}$ ), being
$72 \%$ of the solubilized sugars in the form of cello-oligosaccharides. This last condition was subjected to a multi-stage EH
strategy without improvements in OSY. An endo-glucanase was also tested, but obtained OSY were lower than cellulase
results. Finally, obtained OS demonstrated to stimulate the growth of two Lactobacilli strains. The results show that BPP
pre-treated under mild operational conditions is a good candidate for cello-oligosaccharides production by EH using 1 FPU/g

Abstract
Banana production generates significant amounts of agricultural wastes, being fiber extraction one of the most relevant
alternatives for their valorization. This process produces banana's pseudostem pulp (BPP) as a byproduct, which shows an
interesting composition for the biorefinery's biochemical platform, with high polysaccharides (68\%) and low lignin contents.
This work deals with the enzymatic hydrolysis (EH) of raw and hydrothermally pre-treated BPP, focusing on the production
of oligosaccharides (OS). Raw BPP hydrolysis with cellulase at different dosages rendered only $3.2 \%$ OS yields (OSY).
Pectinase addition has not affected EH performance. On the other hand, EH of hydrothermally pre-treated BPP at $150{ }^{\circ} \mathrm{C}$
and $170{ }^{\circ} \mathrm{C}$ (P150 and P170) allowed to increase OSY up to $28 \%$ (P150, 1 FPU of cellulase/g dry biomass, $12 \mathrm{~h}$ ), being
$72 \%$ of the solubilized sugars in the form of cello-oligosaccharides. This last condition was subjected to a multi-stage EH
strategy without improvements in OSY. An endo-glucanase was also tested, but obtained OSY were lower than cellulase
results. Finally, obtained OS demonstrated to stimulate the growth of two Lactobacilli strains. The results show that BPP
pre-treated under mild operational conditions is a good candidate for cello-oligosaccharides production by EH using $1 \mathrm{FPU} / \mathrm{g}$ DB of cellulase with a simple strategy.
\end{abstract}

Keywords Banana wastes $\cdot$ Cello-oligosaccharides $\cdot$ Cellulose $\cdot$ Endo-glucanase $\cdot$ Multi-stage enzymatic hydrolysis

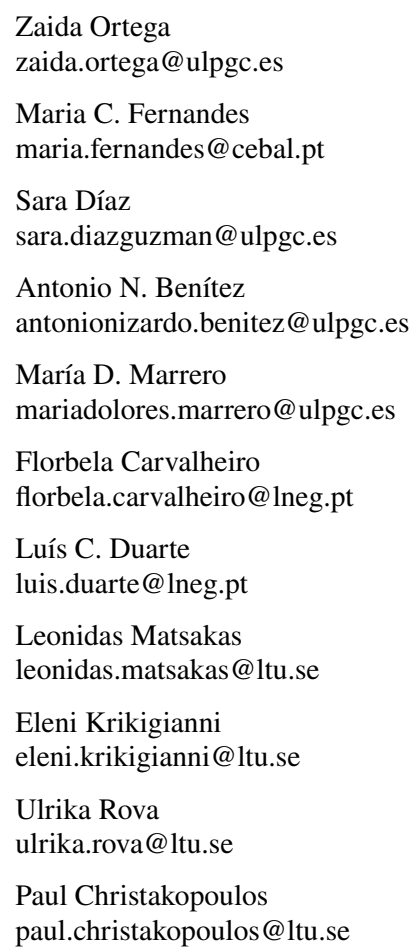

1 Departamento de Ingeniería de Procesos, Universidad de Las Palmas de Gran Canaria. Edificio de Fabricación Integrada, Las Palmas de Gran Canaria, Parque Científico Tecnológico de la ULPGC, Campus universitario de Tafira Baja, 35017 Las Palmas, Spain

2 Departamento de Ingeniería Mecánica, Universidad de Las Palmas de Gran Canaria. Edificio de Fabricación Integrada, Las Palmas de Gran Canaria, Parque Científico Tecnológico de la ULPGC, Campus universitario de Tafira Baja, 35017 Las Palmas, Spain

3 LNEG- Laboratório Nacional de Energia e Geologia, Unidade de Bioenergia, Estrada Do Paço Do Lumiar, 22, 1649-038 Lisboa, Portugal

4 Biochemical Process Engineering, Chemical Engineering, Department of Civil, Environmental and Natural Resources Engineering, Luleå University of Technology, 97187 Luleå, Sweden

5 Centro de Biotecnologia Agrícola E Agro-Alimentar Do Alentejo (CEBAL)/Instituto Politécnico de Beja (IPBeja), Apartado 6158, 7801-908 Beja, Portugal

6 MED-Mediterranean Institute for Agriculture, Environment and Development, CEBAL - Centro de Biotecnologia Agrícola e Agro-Alimentar do Alentejo, Apartado 6158, 7801-908 Beja, Portugal 


\section{Introduction}

Banana crops generate a huge amount of residues, as each plant produces fruit only once in its life. For 1 ton of harvested fruit, around 4 tons of lignocellulosic wastes are generated, being the pseudostem $75 \%$ of this residue [1]. This biomass is usually left in the plantations, having no nutritional value for the soil and generating waste accumulation problems for the next harvesting. Mechanical fiber extraction is one of the most relevant alternatives for the valorization of the pseudostem [2], but fiber is still a low amount of the plant. So, in order to improve the overall valorization of the banana plants, it is necessary to find other uses for this material. The chemical characterization of banana's pseudostem pulp (BPP) has been demonstrated to have an interesting composition for developing a biorefinery's biochemical platform, due to its high polysaccharides content (above 60\%) and low Klason lignin content [3]. Also in this work, the autohydrolysis pre-treatment was successfully applied to BPP, producing a high concentration of oligosaccharides (OS) and a residual solid with improved characteristics for enzymatic hydrolysis (EH).

$\mathrm{EH}$ or its combination with other processes is a way to transform lignocellulosic material into biofuels or other value-added products like enzymes, organic acids, chemicals, pharmaceuticals, and food/feed [4, 5]. Most of the studies published in literature consider EH, preceded by pretreatment and followed by microbial or chemical conversion, as a process to liberate monomeric sugars from cellulose and hemicellulose [6]. However, besides sugar monomers, EH can also produce OS (with potential prebiotics activity) [7]. For example, cello-oligosaccharides (cello-OS), defined as saccharides consisting of 2 to 6 glucose molecules linked by B-1,4-linkages, with cellobiose as the main oligosaccharide unit [8], can be obtained by the EH of cellulose. Although cello-OS as potential prebiotics have not received as much attention as hemicellulose-derived OS such as arabino- and xylo-OS, some studies show that they have different bioactive properties [9]. Cello-OS can provide multiple positive functions toward the host's health, affecting intestinal mucosal architecture, absorption function, barrier integrity, and gut's microflora [9].

There is a limited number of studies in the literature addressing cello-OS production from lignocellulosic materials, and these mainly focus on sugarcane straw [10], corncob residue [8], and forest biomass residues [11-13]. On the other hand, there are some references on the application of EH to the untreated and pre-treated banana pseudostem material [14-19], although these studies aim at the production of fermentable sugars, and no attention was paid to the possibility of obtaining OS, an aspect that is addressed in the present study.
The goal of the present research is to produce OS from BPP and pre-treated BPP and evaluate its capacity to stimulate the growth of probiotic strains. The first approach was to study the initial stages of the EH with cellulase from Trichoderma reesei directly on BPP (due to its low lignin content), varying cellulase dose and reaction time and also assessing the influence of supplementation with pectinase. Aiming to improve the enzymatic hydrolysis yields, a second approach was to study enzymatic hydrolysis with cellulase on pretreated BPP by non-isothermal autohydrolysis at two different final temperatures $\left(150\right.$ and $\left.170{ }^{\circ} \mathrm{C}\right)$, varying enzyme dose and reaction time. As an alternative to the commercial cellulase mixture, EH trials were also performed by using a commercially available purified endo-glucanase from Aspergillus niger. The third approach was a multi-stage $\mathrm{EH}$ with media replacement at different time intervals with the best pre-treated BPP. Finally, the capacity of the biomass-derived cello-OS to stimulate the growth of two Lactobacilli species was assessed.

\section{Material and methods}

\subsection{Feedstock and pre-treated biomass}

Pseudostems from Musa acuminata Dwarf Cavendish (Gran Enana cultivar) were collected from an agro-industrial plantation in Gran Canaria (Spain). Pseudostems were subjected to mechanical fiber extraction using a pilot plant available at the University of Las Palmas de Gran Canaria. Banana's pseudostem pulp (BPP) obtained from fiber extraction, which was the raw material for this study, was characterized in a previous work [3], and its composition is given in Table 1.

BPP was dried to constant weight at $40{ }^{\circ} \mathrm{C}$. A fraction was milled with a knife mill (Fritsch Industriestr, Germany)

Table 1 Chemical composition (\% w/w in dry base) of banana's pseudostem pulp (BPP) and solid fractions obtained after the autohydrolysis of $\mathrm{BPP}$ at $150{ }^{\circ} \mathrm{C}(\mathrm{P} 150)$ and $170{ }^{\circ} \mathrm{C}(\mathrm{P} 170)$ [3]

\begin{tabular}{lrlr}
\hline Component (\% w/w in dry base) & $\mathrm{BPP}$ & $\begin{array}{l}\mathrm{P} 150 \\
\log \mathrm{R}_{0}=2.3\end{array}$ & \multicolumn{1}{l}{$\begin{array}{l}\mathrm{P} 170 \\
\log \mathrm{R}_{0}=3.01\end{array}$} \\
\hline Glucan & 47.39 & $48.21 \pm 0.08$ & $47.89 \pm 1.63$ \\
$\quad$ Starch & 22.17 & $12.46 \pm 1.17$ & $1.52 \pm 0.12$ \\
Hemicellulose & 14.98 & $14.97 \pm 0.71$ & $21.10 \pm 0.74$ \\
$\quad$ Xylan & 7.65 & $10.43 \pm 0.2$ & $10.33 \pm 0.36$ \\
$\quad$ Arabinan & 6.61 & $4.54 \pm 0.51$ & $5.05 \pm 0.53$ \\
$\quad$ Acetyl groups & 0.79 & - & $5.73 \pm 0.15$ \\
Klason lignin & 7.92 & $14.41 \pm 0.16$ & $17.33 \pm 0.47$ \\
Ash & 15.44 & $8.88 \pm 0.11$ & $7.64 \pm 1.75$ \\
Enzymatic digestibility $(\%)^{*}$ & 73.25 & $78.62 \pm 0.91$ & $83.2 \pm 2.54$ \\
\hline
\end{tabular}

*Evaluated according to NREL/TP-510-42,629 protocol [3] 
to particles smaller than $6 \mathrm{~mm}$ for autohydrolysis, and the other part was ground in an Ultra Centrifugal Mill ZM200 (Retsch, Germany) to particles smaller than $0.5 \mathrm{~mm}$, for EH. Autohydrolysis pre-treatment was performed as indicated in [3] with two final temperatures, $150{ }^{\circ} \mathrm{C}$ and $170{ }^{\circ} \mathrm{C}$, under non-isothermal conditions, using a solid/liquid rate of 1/11. The obtained solids were washed with twice the amount of water, pressed again, and then dried at $40{ }^{\circ} \mathrm{C}$ for their use in the $\mathrm{EH}$ (denoted as P150 and P170). The chemical characterization of banana's pseudostem pulp (BPP), P150, and $\mathrm{P} 170$ was conducted in the afore mentioned paper and can be also found in Table 1 .

\subsection{Reagents}

Glucose, xylose, arabinose, and cellobiose were purchased from Sigma-Aldrich. Cello-OS (cellotriose, cellotetraose, cellopentaose, and cellohexaose) were purchased from Megazyme. Other reagents used during the experiments were all from analytical grade. Cellulase from Trichoderma reesei ATCC 26,921 (54 FPU/mL; $\beta$-glucosidase activity $19 \mathrm{U} / \mathrm{mL}$; endo-glucanase activity $2138 \mathrm{U} / \mathrm{mL}$ ), from Sigma-Aldrich, pectinase ENARTIS ZYM COLOR PLUS, from Enartis, and endo-1,4- $\beta$-D-glucanase E-CELAN from Megazyme (70U/ mg) from Aspergillus niger were used.

\subsection{Enzymatic hydrolysis}

EH tests were carried out using 5\% (w/v) of dry biomass loading and total volume of $10 \mathrm{~mL}$, in $50-\mathrm{mL}$ capped Erlenmeyer flasks. The reaction medium was composed of $0.05 \mathrm{M}$ citrate buffer ( $\mathrm{pH} 4.8$ ), the appropriate volume of enzyme and sodium azide $(0.02 \% \mathrm{w} / \mathrm{v})$ as an anti-microbial agent. Enzymatic activities were measured according to Ghose [20]. Assays were performed in an orbital shaker incubator (TEQ, Portugal) at $50{ }^{\circ} \mathrm{C}$ at $150 \mathrm{rpm}$. Samples of $0.5 \mathrm{~mL}$ were withdrawn at regular intervals for $24 \mathrm{~h}$, from the same flask as previous work showed a great variability in the results when using independent flasks. All EH assays were performed in duplicates. The initial time $(t=0 \mathrm{~h})$ was considered as the blank (biomass and enzyme blank) in order to correct the results to any free saccharides present in the biomass or in the enzymes. The withdrawn samples were boiled for $5 \mathrm{~min}$ and rapidly cooled to inactivate the enzymes. The samples were then centrifuged at $13,000 \times g$, and the hydrolysates were filtered through $0.20-\mu \mathrm{m}$ filters and analyzed by HPLC for glucose quantification before post-hydrolysis and then subjected to post-hydrolysis for OS quantification as indicated in Sect. 2.5.1. Enzymatic hydrolysis yield was calculated according to Eqs. 1 and 2. All experiments used the above condition. Figure 1 shows a scheme of the

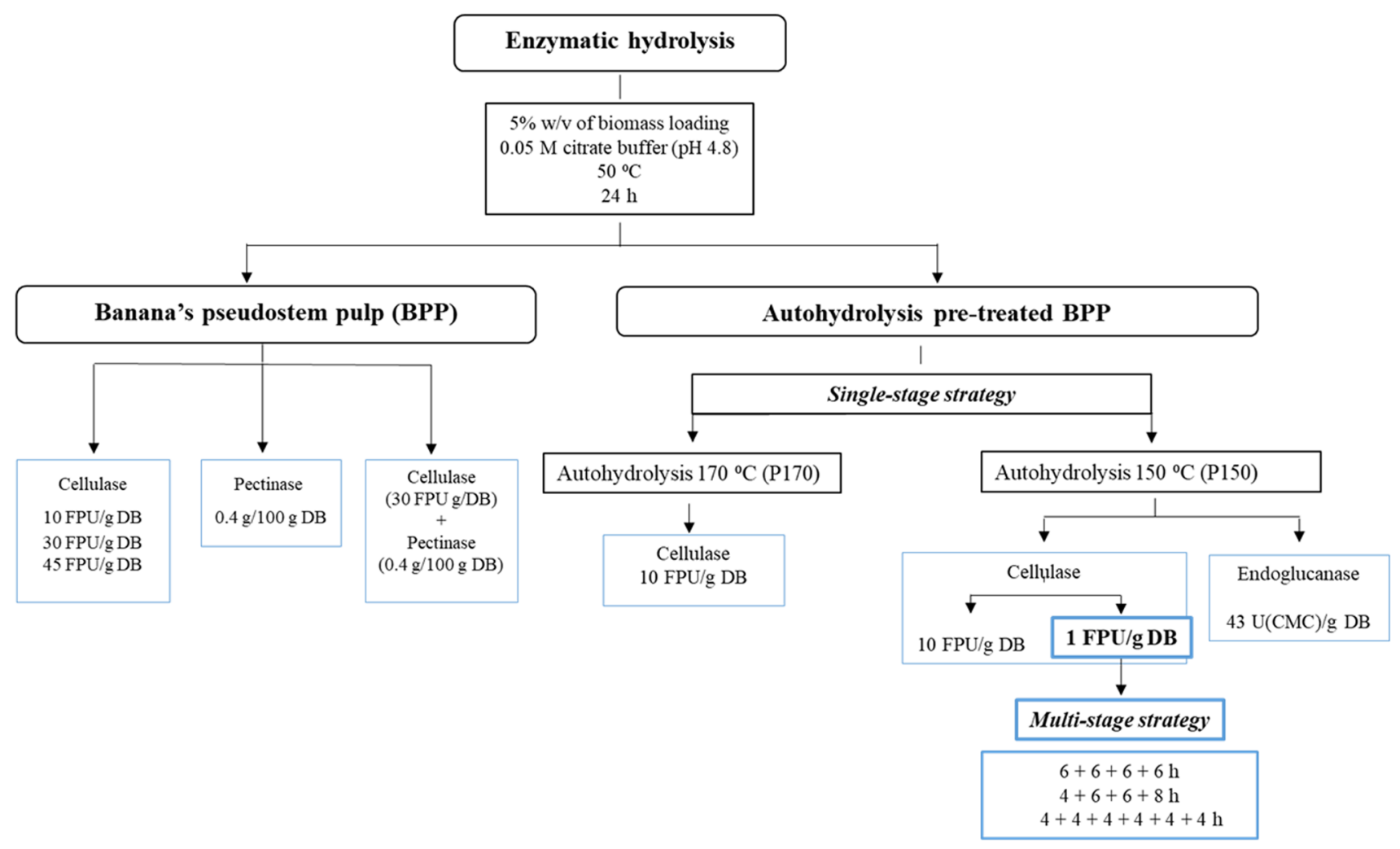

Fig. 1 Enzymatic hydrolysis strategies employed during present study for oligosaccharide production from BPP and pre-treated BPP 
different enzymatic hydrolysis strategies employed during present study.

\subsubsection{Enzymatic hydrolysis of BPP}

EH of untreated material (milled to particles smaller $0.5 \mathrm{~mm}$ ) was evaluated at different cellulase dosages: 10 , 30 , and $45 \mathrm{FPU} / \mathrm{g}$ of dry biomass (DB). In addition, a pectinase was used with the untreated material in the presence (30 FPU/g DB) or absence of cellulase. Pectinase solution was prepared by dissolving $5 \mathrm{~g}$ of the pectinase in $50 \mathrm{~mL}$ of citrate buffer $0.1 \mathrm{M}(\mathrm{pH}=5.8)$. Pectinase was added to the medium previously described in a dose of $0.4 \%$ (g pectinase/100 g DB). Samples were taken as described before, and glucose and cello-OS were measured by HPLC.

\subsubsection{Enzymatic hydrolysis of pre-treated BPP}

Pre-treated BPP were submitted to EH using the particle size resulting after the pre-treatment without intermediate milling. For P170, 10 FPU/g DB was used. On the other hand, EH of P150 was carried out with 10 and 1 FPU/g DB of cellulase.

P150 was also hydrolyzed using E-CELAN, an endo- $\beta$ glucanase, at a dosage of $43 \mathrm{U}(\mathrm{CMC}) / \mathrm{g}$ DB. For the assay, the enzyme was diluted to $11 \mathrm{~mL}$ with sodium acetate buffer $(100 \mathrm{mM}, \mathrm{pH}=4.5)$ containing $0.5 \mathrm{mg} / \mathrm{mL}$ bovine serum albumin (BSA), as specified by the manufacturer. Endo- $\beta$ glucanase activity was measured by carboxymethyl cellulose (CMC) assay [20] after the dilution of the enzyme, and the obtained activity was $14 \mathrm{U} / \mathrm{mL}$.

\subsubsection{Multi-stage enzymatic hydrolysis of pre-treated BPP}

For the multi-stage enzymatic hydrolysis study, P150 was used with $1 \mathrm{FPU} / \mathrm{g}$ DB of cellulase. In this case, 50 -mL centrifuge tubes were used to facilitate the replacement of the media. At the end of each stage, the solid was separated from the liquid phase by centrifugation, and the removed supernatant was replaced with fresh buffer $(0.05 \mathrm{M}$ citrate buffer $\mathrm{pH}$ 4.8 and $0.02 \%$ sodium azide) without any enzyme, to restore the initial volume and perform the following enzymatic stage. The EH was carried out for $24 \mathrm{~h}$ with the replacement of the media at different time intervals. In the first strategy, a six-stage EH was carried out with replacements each $4 \mathrm{~h}$. The second one was a four-stage process with replacements each $6 \mathrm{~h}$, and the third one was also a four-stage process with different time intervals $(4+6+6+8 \mathrm{~h})$. The supernatants obtained in each stage were analyzed by HPLC for monosaccharides and OS quantification after post-hydrolysis and also directly as it is, for evaluation degree of polymerization (DP), as indicated in Sect. 2.5.1. The EH yield obtained in each stage was calculated according to Eqs. 1 and 2, taking into consideration the volume recovered in each stage. The overall yield obtained in each strategy was obtained as the sum of the individual yields obtained in each stage.

\subsection{Stimulation of the growth of probiotic bacteria on BPP hydrolysate}

Two probiotic strains, Lactobacillus gasseri DSM20077, from DSMZ (Braunschweig, Germany), and Lactobacillus plantarum ATCC 8014, from ATCC (Manassas, VA, USA), were used in order to determine to what extent the cello-OS, produced by EH of BPP under the optimal conditions, can be used as carbon sources by these bacteria. These strains were chosen due to their ability to efficiently grow on commercial cellobiose [12]. The medium for both Lactobacillus strains' stock cultures was 232 DSMZ (Man-Rogosa-Sharpe (MRS) medium with cysteine). The hydrolysate was tested at an initial carbohydrate (cellobiose + glucose) concentration of $2 \%(\mathrm{w} / \mathrm{v})$ in MRS media prepared at $\mathrm{pH}$ 6.0, in the absence of any other carbohydrate. The obtained media was sterilized using $0.22 \mu \mathrm{m}$ pore size filters. For the inoculation of the media, bacteria cells grown in glucose pre-cultures were centrifuged $(1800 \times \mathrm{g}$ for $10 \mathrm{~min})$, collected, and resuspended in $20 \mathrm{~mL}$ of the sterilized media, to obtain an initial optical density (OD) of 0.3 . The cultures were incubated at $36^{\circ} \mathrm{C}$, without agitation. The growth rate was monitored by $\mathrm{OD}$ at $600 \mathrm{~nm}\left(\mathrm{OD}_{600 \mathrm{~nm}}\right)$ and glucose and cellobiose consumption, as well as fermentation products (lactic acid, acetic acid, etc.) were analyzed by HPLC. All tests were run in duplicates.

\subsection{Analytical methods}

\subsubsection{High-performance liquid chromatography (HPLC)}

Hydrolysates from EH and fermentation studies were analyzed by HPLC. Monosaccharides (glucose, xylose, arabinose), cellobiose, and short-chain fatty acids (SCFA) resulting from fermentation (lactic acid, acetic acid, butyric acid, and propionic acid) concentrations were analyzed by a Merck Hitachi LaChrom HPLC System (Tokyo, Japan) equipped with refraction index (L7490) detector. An Aminex HPX-87H $(7.8 \times 300 \mathrm{~mm})$ cation exchange column, preceded by a $50 \times 7.8 \mathrm{~mm}$ guard column with the same filling (BioRad, USA), was used at $50{ }^{\circ} \mathrm{C}$ with $\mathrm{H}_{2} \mathrm{SO}_{4} 5 \mathrm{mM}$ as eluent with a flow rate of $0.6 \mathrm{~mL} / \mathrm{min}$.

For OS quantification, an aliquot sample was post-hydrolyzed with $4 \%(\mathrm{w} / \mathrm{w}) \mathrm{H}_{2} \mathrm{SO}_{4}$ at $121{ }^{\circ} \mathrm{C}$ for $60 \mathrm{~min}$, and the increase in sugar monomers was used to determine the OS concentration. To assess the OS polymerization degree, enzymatic hydrolysates were injected in Phenomenex Rezex RSO-Oligosaccharide $\mathrm{Ag}^{+}(200 \times 10 \mathrm{~mm})$ column at $80^{\circ} \mathrm{C}$, preceded by $60 \times 10 \mathrm{~mm}$ guard column with the same filling. 
Ultrapure water at $0.3 \mathrm{~mL} / \mathrm{min}$ was used as eluent. Calibration was done with standards mentioned in Sect. 2.2.

\subsection{Calculations}

EH yields for monomers (glucose) were calculated according to Eq. 1:

$G Y(\%)=\frac{\text { glucose obtained }}{\text { potential glucose in the substrate }} \times 100$

where potential glucose in the substrate is calculated considering total glucan content in the solid and the molecular weight ratio from glucan to glucose (180/162).

Enzymatic hydrolysis yield in oligosaccharides, OSY, was calculated by the Eq. 2:

$\operatorname{OSY}(\%)=\frac{\text { Oligosaccharides obtained }}{\text { glucan in the substrate }} \times 100$

where oligosaccharides content was obtained by the increase in sugar monomers measured after post-hydrolysis, as indicated in Sect. 2.5.1.

Total enzymatic yield (TY) was calculated as the sum of OSY and GY. Oligosaccharides selectivity was calculated by Eq. 3:

OSselectivity $=\frac{\mathrm{OSY}}{\mathrm{TY}}$

The growth rate $(\mu)$ of the bacteria was calculated by Eq. 4:

$\mu=\frac{\left(\ln O D_{2}-\ln O D_{1}\right)}{\left(t_{2}-t_{1}\right)}$

where $\mathrm{OD}_{1}$ and $\mathrm{OD}_{2}$ were taken in the exponential section of the bacterial growth curve, corresponding to time 1 and 2 , respectively.

\subsection{Statistical analysis}

Statistical comparisons were conducted using Tukey's test. The significance of the difference between means was determined by Tukey's test using R-Commander (R-Studio Software).

\section{Results and discussion}

\subsection{Enzymatic hydrolysis of banana's pseudostem pulp}

Due to the high enzymatic digestibility of the untreated BPP (Table 1) [3], direct EH of the raw material was evaluated for monosaccharide and oligosaccharide production. Different dosages of cellulase, as well as the use of a pectinase alone and in combination with cellulase, were evaluated. Increasing the dosage of cellulase up to a certain point can enhance the yield and ratio of hydrolysis but would also significantly increase the cost of the process. Cellulase loadings usually vary from 7 to $33 \mathrm{FPU} / \mathrm{g}$ substrate, depending on the type and concentration of substrates [21]. A cellulase dosage of $10 \mathrm{FPU} / \mathrm{g}$ cellulose is often used because it provides a hydrolysis profile with high levels of glucose yield in a reasonable time (48-72 $\mathrm{h}$ ) at a reasonable enzyme cost [22]. In the present study, 10, 30, and 45 FPU/g DB were tested for untreated BPP, as a strategy to avoid the pre-treatment, and the monosaccharides and OS production were evaluated. The study was performed for $24 \mathrm{~h}$, since it is known that the enzyme has a high activity within the first $24 \mathrm{~h}$ and the OS production takes place in the first stages of EH [15].

Figure 2 shows the time evolution of total enzymatic hydrolysis yield (TY) and enzymatic hydrolysis yield in oligosaccharides (Eq. 2), at the different enzyme dosages tested. No release of xylose and arabinose was detected during the EH. As expected, increasing enzyme dosages resulted in higher TY, which was observed through the $24 \mathrm{~h}$ hydrolysis. However, this improvement was relatively low in comparison with the enzyme dosage rise, increasing from 10 to $16 \%$ when the dosage was increased from 10 to 45 FPU for $24 \mathrm{~h}$, which may not be cost-effective. This behavior can be associated with the non-productive adsorption of cellulase either on starch or the lignin [23]. Concerning OS production, as shown in Fig. 2, most of hydrolyzed polymers was in a monomeric form and not as OS. The maximum yield achieved in OS production was lower than $4 \%$ of the total glucan, with no significant improvement when higher enzyme dosages were used ( 30 and 45 FPU/g DB). The fact that increasing enzyme dosages improved TY but not OSY can be probably partially attributed to the high degree of crystallinity and polymerization of biomass from banana wastes [24], which does not allow the endo-glucanase to attack the internal bonds of the chain, being only the exoglucanase able to break chain-ends.

The yields obtained, even using a dosage of $45 \mathrm{FPU} / \mathrm{g}$ DB, were low compared with potential enzymatic digestibility of the raw material (73\%) obtained in the enzymatic digestibility assay [3], which can be attributed to different factors. Firstly, it is important to highlight that during those tests, cellulases were supplemented with Novozyme 188, which contain high amylase activity [25] that can hydrolyze alpha bonds in starch, producing additional glucose during the hydrolysis. In addition, higher enzyme load (60 FPU/g DB) and longer reaction time (72 h) was used, as the focus was different (i.e., production of glucose instead of OS). Also, in this study the presence of starch that was not hydrolyzed might have limited the productive adsorption of 
Fig. 2 BPP enzymatic hydrolysis yields for different enzyme dosages $(10,30$, and $45 \mathrm{FPU} / \mathrm{g}$ of DB). Solid lines refer to total yield (TY), and dotted lines correspond to oligosaccharide yields (OSY)

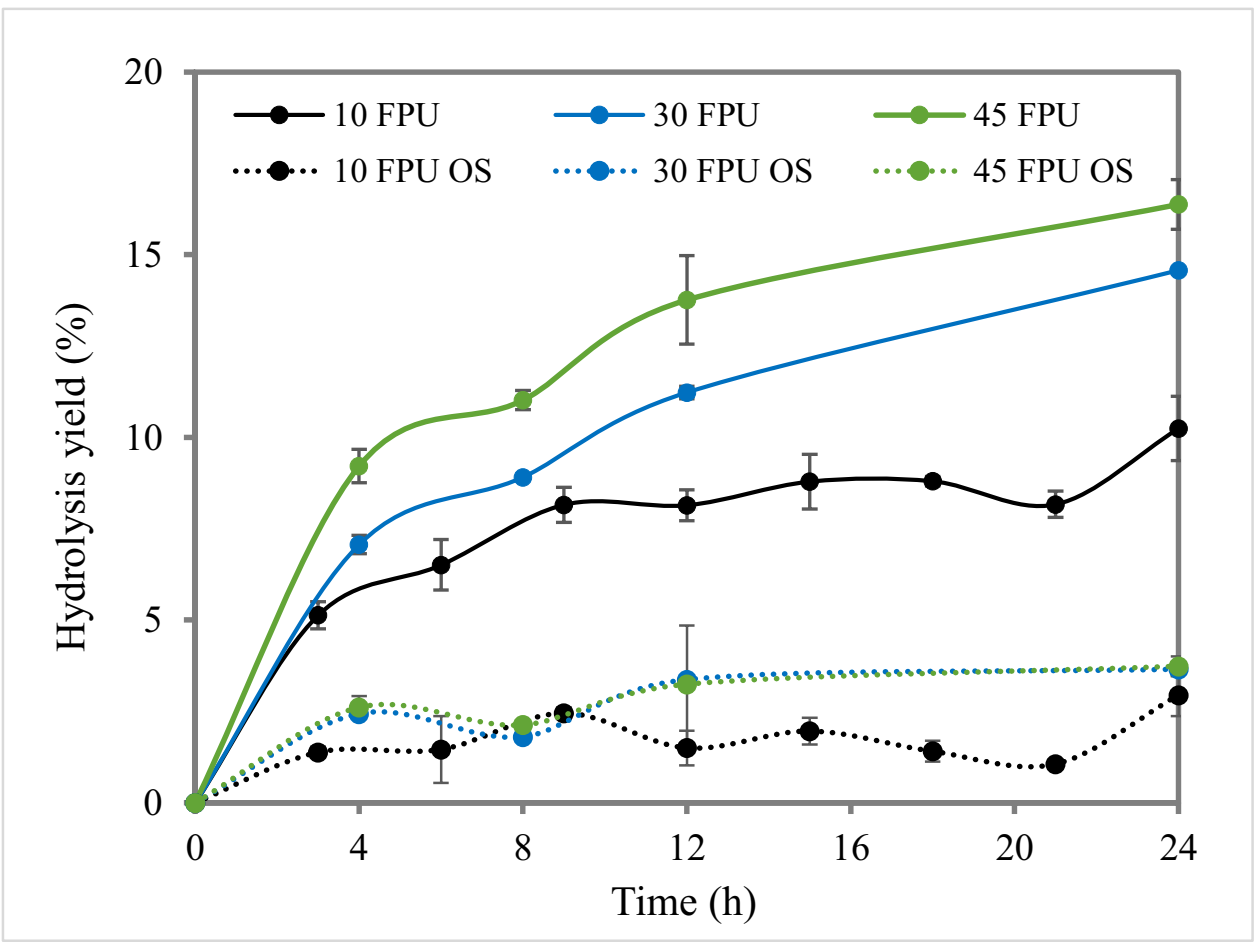

the cellulase enzyme. Finally, glucanases inhibition could be expected due to the low $\beta$-glucosidase activity (19 U/ $\mathrm{mL}$ ) of the enzyme used for the assays, which could result in cellobiose accumulation that in turn inhibited cellulase [26]. However, HPLC chromatogram did not show a high presence of cellobiose in the reaction medium, being most of glucans found as glucose, as commented.

The use of cellulases with other enzymes in the hydrolysis of cellulosic materials has been extensively studied [21]. For example, Ghose and Bisaria [27] and Beldman [28] reported a significant increase in the extent of cellulose conversion using a mixture of hemicellulases or pectinases with cellulases. In this study, a pectinase was used with the BPP in the presence (30 FPU/g DB) and absence of cellulase, in order to evaluate if pectinase would have any effect in saccharification, not only by increasing the sugars obtained but also by improving the mixing and the contact between biomass and enzyme. However, results revealed that pectinase used in this study did not affect neither the TY nor OS production (data not shown).

Therefore, it was concluded that enzymatic hydrolysis of untreated BPP does not allow obtaining good yields using enzyme loadings economically viable. Although compared to other lignocellulosic biomass, banana wastes have generally lower lignin contents (component that has been related to the recalcitrance of a biomass), it has a more fibrous nature, which limits the rate of $\mathrm{EH}$ [24]. The pre-treatment is, therefore, a key factor for effective $\mathrm{EH}$, as also observed by other authors working with banana crop byproducts [29,
30]. For example, Shimizu [30] obtained a maximum of $15.9 \%$ enzymatic hydrolysis yield after $72 \mathrm{~h}$ for untreated pseudostem with $15 \mathrm{FPU} / \mathrm{g}$ cellulase supplemented with cellobiase, value which is comparable to the $16.4 \%$ yield obtained in this study for $24 \mathrm{~h}$ at 45 FPU.

\subsection{Enzymatic hydrolysis of pre-treated BPP with cellulase}

Apart from untreated BPP, pre-treated material via autohydrolysis was used. The pre-treatment conditions were chosen on the basis of previous results [3]: autohydrolysis at $150{ }^{\circ} \mathrm{C}$ and at $170{ }^{\circ} \mathrm{C}$. The compositions of both fractions are shown in Table 1. The autohydrolysis pre-treatment removed ashes and extractives, and a solid enriched in hemicellulose, glucan, and lignin was obtained. The autohydrolysis pre-treatment also allowed improving the enzymatic digestibility of the material, which increased $10 \%$ at the highest temperature (Table 1).

The pre-treated materials (P170 and P150) were subjected to EH, at an enzyme dosage of $10 \mathrm{FPU} / \mathrm{g}$ DB. Figure $3 \mathrm{a}$ and b show the evolution of glucose yield (GY), oligosaccharide yield (OSY), and the total yield (TY) obtained for P170 and P150, respectively. A higher dosage of enzyme was tested, but results are not shown, since it did not improve neither TY nor OSY, for both pre-treated biomass. The higher values of yields obtained shows the advantage of using a pretreatment, which not only allows to attain much better yields but also reducing treatment time or enzyme dosage while 

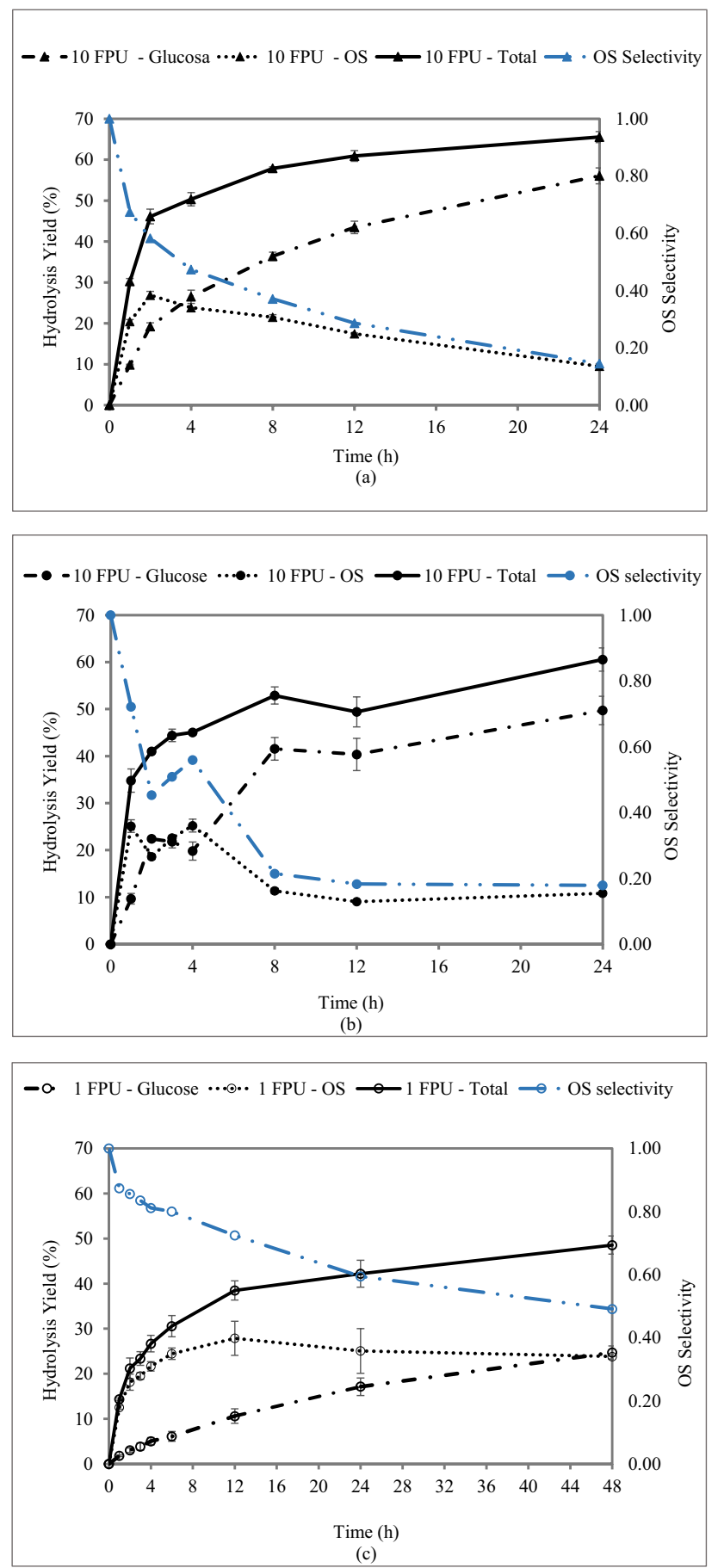

Fig. 3 Enzymatic hydrolysis yield obtained with pre-treated BPP by autohydrolysis at $170{ }^{\circ} \mathrm{C}$ (P170) at an enzyme dosage of $10 \mathrm{FPU} / \mathrm{g}$ DB (a) and pre-treated BPP by autohydrolysis at $150{ }^{\circ} \mathrm{C}(\mathrm{P} 150)$ at an enzyme dosage of $10 \mathrm{FPU} / \mathrm{g}$ DB (b) and $1 \mathrm{FPU} / \mathrm{g}$ DB (c). Solid lines refer to total yield (TY), dotted lines correspond to oligosaccharide yields (OSY), dash-dot lines to glucose yields (GY), and dash-dot lines to OS selectivity

keeping the effectiveness. In this occasion, although higher amounts of OS were obtained, most of dissolved material was rapidly converted to monosaccharides. The kinetic was quite similar for both pre-treated fractions. At the beginning of the reaction, where the rate of hydrolysis is higher due to preferential hydrolysis of the amorphous region, OS are produced in a higher amount than glucose, due to the action of the endo-glucanases in the amorphous region. However, these OS are converted into glucose over the time. This breakdown was slower in the case of P150. While for P170 (Fig. 3a), OS were generated in the first $2 \mathrm{~h}$ and their breakdown started rapidly, the OS produced for P150 remained stable during the first $4 \mathrm{~h}$ (Fig. 3b). Analyzing the total yields, the highest TYs obtained ( $24 \mathrm{~h}$ of hydrolysis) were $65.5 \%$ for $\mathrm{P} 170$ and $60.5 \%$ for P150. P150 was less affected in structure, due to less severe conditions, and it is reasonable that the yields were slightly lower. Both yields were lower than potential enzymatic digestibility (Table 1), fact which can be attributed, in part, to the insufficient reaction time. For instance, a study with alkali pre-treated banana pseudostem and enzyme loading of $30 \mathrm{FPU} / \mathrm{g}$ of solid [29] showed an increase in the enzymatic yield from around 65 (in $24 \mathrm{~h}$ ) to $84 \%$ (in $110 \mathrm{~h}$ ). Moreover, a lower solid-liquid rate was used in enzymatic digestibility assay, making mass transfer easier, and a smaller particle size was used (increasing available surface), which turns the process faster. On the other hand, as the enzymatic digestibility assay was done in the presence of Novozyme 188, some extra sugars could be produced coming from remaining starch/hemicellulose for P150. Comparing both pre-treatments, autohydrolysis at $150{ }^{\circ} \mathrm{C}$ presented some advantages: the use of less severe conditions, with the consequent energy savings, and the obtaining of higher OS selectivity ( 0.58 for P170 vs 0.72 for P150, Fig. 3a and b, respectively) while keeping the OSY, around 25\% for both pre-treated fractions. In fact, the analysis of OS selectivity shows that with $10 \mathrm{FPU}$, the selectivity decreases very quickly after the first $4 \mathrm{~h}$, to values lower than 0.5 .

Given the advantages of P150, the possibility of reducing the enzyme dosage (and consequently the cost) in the EH of this material was evaluated. Figure $3 \mathrm{c}$ shows evolution of GY, OSY, TY, and OS selectivity obtained during EH with $1 \mathrm{FPU} / \mathrm{g}$ DB. In this case, the reaction was evaluated until $48 \mathrm{~h}$. Due to the very low enzyme dosage, the hydrolysis rate was lower, and the maximum TY achieved was below that the one obtained with $10 \mathrm{FPU} / \mathrm{g}$ DB (49\% in contrast with $61 \%$ ); however, if the analysis is made per unit of enzyme used, we obtained $49 \%$ against $6.1 \%$ when using 1 or 10 FPU, respectively. Also, OS selectivity decreases slowly in comparison to enzyme hydrolysis with $10 \mathrm{FPU} / \mathrm{g} \mathrm{DB}$, reaching 0.5 at $48 \mathrm{~h}$. The differences between TY are not as big as the ones obtained by other authors when increasing the enzyme dosage, for example, [31] tripled the saccharification yield when doubling the enzyme dosage (3 FPU/g) working with pre-treated birch. This very low dosage of 
cellulase allowed to obtain similar OSY $(27.87 \pm 3.76 \%$ vs $25.23 \pm 1.38 \%$ for 1 and 10 FPU, respectively) and OS selectivity ( 0.72 for both dosages) with the difference that longer reaction time was needed to achieve the maximum yield in OS ( $1 \mathrm{~h}$ vs $12 \mathrm{~h}$ ). Analyzing per unit of enzyme maximum OSY was 2.5 vs $28 \%$ and OS selectivity was 0.072 vs 0.72 for 10 and $1 \mathrm{FPU}$, respectively. This huge difference is probably due to the very low amount of $\beta$-glucosidase present in the media, which avoid OS breakage into glucose, as observed for $10 \mathrm{FPU} / \mathrm{g} \mathrm{DB}$, representing an advantage in the present study. If instead of OSY, OS selectivity is prioritized (an interesting parameter, especially when alternative approaches, like medium replacement are followed [8]), the maximum value obtained was 0.87 (with an OSY of 12.56\%) for the shortest time evaluated $(1 \mathrm{~h})$.

Hydrolysates characterization of same condition, from posterior experiments (multi-stage strategy), revealed that most of the cello-OS was cellobiose (31\%), with small amount of DP3-6 (8\%). During the EH of cellulose, obtained cello-OS in an intermediate step are hydrolyzed quickly to glucose, and it is necessary to quickly separate the celloOS from the reaction mixture before they are completely hydrolyzed to glucose $[32,33]$. In this occasion, in which the presence of $\beta$-glucosidase in the reaction media was very low, the high content of glucose was also probably the result of the action of the exo-glucanases present in the enzymatic complex, activities that were not quantified in the cellulase characterization in the present work. Cellulase from Trichoderma reesei (the one used in this work) is known to have higher exo- $\beta$-glucanase than endo- $\beta$-glucanase activity [33]. Further evidence of this is the fact that, for example, between 24 and $48 \mathrm{~h}$, the reduction in the concentration of OS would correspond to an increase of glucose of $0.33 \mathrm{mg} / \mathrm{mL}$; however, the increase of glucose in this interval was $2.04 \mathrm{mg} /$ $\mathrm{mL}$.

The results obtained are comparable with those previously published addressing cello-OS production from lignocellulosic material. For example, the saccharification of organosolv-pre-treated birch biomass in similar conditions as this work produced an OSY of $18.5 \%$ and $10.9 \%$ for 24 and $48 \mathrm{~h}$, respectively, corresponding to OS selectivity of 88 and $83 \%$, respectively [11]. The higher OS selectivity for birch can be explained by the higher glucan content (77.9\%) when compared to present biomass (48.21\%).

\subsection{Enzymatic hydrolysis of pre-treated BPP with endo-glucanase}

A purified endo-glucanase (E-CELAN) was also used in this work, as the absence of $\beta$-glucosidase and exo- $\beta$ glucanase activities would lead to maximizing OS production and selectivity. The endo-glucanase enzyme dosage chosen was calculated to obtain similar CMC activity to the one provided by the cellulase at $1 \mathrm{FPU} / \mathrm{g} \mathrm{DB}$. The yields obtained with the endo-enzyme are relatively low when compared to cellulase action (data not shown), although a step increase was observed in OSY between 24 and $48 \mathrm{~h}$, which increased from 1.33 to $11.53 \%$, and in TY (from 1.42 to $13.94 \%$ ). The low enzyme dosage and the use of a mono-enzyme might require longer reaction times. In this occasion, cellobiose accumulation was not observed during the $48 \mathrm{~h}$ studied. The low cellobiose detected (coming from exo-glucanase activity), the low glucose yields (associated to $\beta$-glucosidase), and the high OS selectivity ( 0.83 for $48 \mathrm{~h}$ ) can be attributed to high enzyme purity. Equivalent results were obtained working with cellulase at a dosage of 1 FPU/g DB and $1 \mathrm{~h}$ of treatment (12.56\% of OSY and an OS selectivity of 0.87 ) but with different profiles of DP for both hydrolysates. In the case of using the cellulase, as said, most of cello-oligosaccharides were as cellobiose. However, the hydrolysate produced by the endo-glucanase did not present OS with lower DP than 6, as observed in the chromatogram obtained with the Phenomenex Rezex RSO-Oligosaccharide column.

Enzyme complexes are usually optimized to maximize sugar production, and no references have been found using this endo-enzyme without additional supplementation; so, results obtained cannot be compared with any other existing data. This endo-glucanase enzyme was used, for example, in the saccharification of pre-treated rice straw supplemented with endo- $\beta$-glucosidase and $\beta$-glucosidase [34]. In the case of cello-OS production, combination of purified enzymes have been used by other authors $[10,12]$, although the possibility of tuning commercially available cellulase mixtures to produce cello-OS has been proposed as a better option [11]; in any case, there are still some barriers that have hindered the scaling-up of the process.

\subsection{Multi-stage enzymatic hydrolysis of pre-treated BPP}

A multi-stage EH process was investigated in order to upgrade the production of cello-OS. The study was carried out using the optimized conditions previously determined (P150, 1 FPU). The total reaction time of $24 \mathrm{~h}$ evaluated in the single-stage hydrolysis was divided in separated stages. Under this strategy, it was expected to improve the cello-OS production due to different factors. On the one hand, the breakage of OS produced could be avoided by their recuperation from the reaction medium. Secondly, the possible inhibition on the exo-glucanases and endo-glucanases produced by the presence of the reaction products could be reduced due to the removal of part of them. Finally, as $\beta$-glucosidase, unlike exo-glucanases and endo-glucanases, exhibits very low binding affinity to cellulosic substrates due to the lack of cellulose-binding domain, the low amount of this enzyme 
could be selectively removed from the liquid phase during the replacement, contributing to avoid the rupture of the OS produced into glucose. The first and the third exposed aspects could improve the OS selectivity of the process, while the second one could improve the overall yield.

Table 2 shows the overall TY, GY, and OSY (calculated as the sum of the yields obtained in each stage) obtained in the different strategies.

If the results obtained for $24 \mathrm{~h}$ of hydrolysis in the single-stage strategy are used for comparison, the advantage of using a multi-stage strategy can be observed, although statistical analysis does not seem to find significant differences. In all multi-stage strategies, OSY are similar but OS selectivity is around 10 units higher. This means that the replacements avoided the rupture of the OS generated by their recuperation from the media before being converted into glucose.

Comparing with $12 \mathrm{~h}$ single-stage hydrolysis, however, the multi-stage strategy did not bring any improvement. Notable improvements in the cello-OS yield or TY were not observed under any of the multi-stage strategies, comparing with single-stage, which could mean that inhibition problems did not exist in single-stage strategy. The concentration of glucose and OS were quite low in the last stages, and, although some extra OS are generated (Online Resources), most of them were produced in the first $12 \mathrm{~h}$, as also happened in single-stage strategy.

Concerning the $\beta$-glucosidase removal, although it can be entrapped within the tridimensional matrix of the pre-treated lignin [35], most of it is expected to have been removed with the replacements. The fact that no great differences were observed with its removal confirms that working with so low levels of cellulase should not be a problem and that the exo-glucanase action can be the main responsible of the high amount of glucose. The same conclusion was obtained in the single-stage study.

This could be explained by the fact that single-stage assay, with $1 \mathrm{FPU} / \mathrm{g} \mathrm{DB}$, could have achieved the best condition for OS production.
Therefore, the use of multi-stage strategy, with its related complexity, is not justified for BPP. If the $12 \mathrm{~h}$ single-stage strategy is compared with the multi-stage, both yield in OS production and the OS selectivity are very close, and so it seems that the single strategy constitutes a better treatment strategy. The combination of yields and selectivities in OS production shown here (28\% cello-OS yield, corresponding to $134.48 \mathrm{mg}$ of COS per $\mathrm{g}$ of raw material, with a OS selectivity of 0.72 using P150, $1 \mathrm{FPU} / \mathrm{g}$ DB for $12 \mathrm{~h}$ ) are comparable to those obtained in literature, with the advantage that a very low load of enzyme and a simpler strategy were used in this case. In general, there is always a compromise between OS selectivity and OSY. For example, Barbosa et al. [10] employed a combination of different endo-glucanases and with lactose and copper as additives, with hydrothermally pretreated sugarcane straw, and obtained almost a $100 \%$ of OS selectivity but just a $6.0 \%$ of OSY. Karnaouri et al. [13] purposed a fine-tuning of the commercially available enzyme mixture Celluclast through $\mathrm{pH}$ modification, multi-stage hydrolysis with buffer exchange, and addition of $\beta$-glucosidase inhibitor. They achieved a cellobiose-rich product with a high cellobiose to glucose ratio (37.5) and a cellulose conversion to cellobiose of $9.78 \%$ by utilizing organosolv-pre-treated birch biomass; they were able to obtained higher conversions (up to $35.2 \%$ ), although with a much lower cellobiose to glucose ratio (3.3). The highest OSY found was obtained by Chu et al. [8] who achieved a OSY of $51.78 \%$ with an OS selectivity of $68.53 \%$ by using a process of adsorption-separation (for selective removal of $\beta$-glucosidase) combined with a multi-stage enzymatic hydrolysis the corncob residues of xylo-oligosaccharides manufacture.

This reflects that BPP is a good candidate for cello-OS production by using the methodology applied in the present study. The yields could be improved using a different enzyme with higher endo-activity or by a later purification step to improve the ratio OS/glucose.
Table 2 Enzymatic hydrolysis yield (\%) of P150 with a cellulase dosage of $1 \mathrm{FPU} / \mathrm{g}$ DB obtained under different strategies of media replacement. The overall total yield (TY), oligosaccharide yield
(OSY), and glucose yields (GY) are indicated together with OS selectivity. Different letters within each variable indicate significance at Tukey test $(p \leq 0.05)$

\begin{tabular}{|c|c|c|c|c|c|c|c|c|}
\hline Strategy & $\begin{array}{l}\text { Overall } \\
\text { OSY (\%) }\end{array}$ & & Overall GY (\%) & & Overall TY (\%) & & OS selectivity & \\
\hline \multicolumn{9}{|l|}{ Multi-stage } \\
\hline $6+6+6+6 h$ & $29.80 \pm 0.44$ & A & $12.74 \pm 0.44$ & $\mathrm{AB}$ & $42.54 \pm 0.33$ & A & $70.05 \pm 0.81$ & A \\
\hline $4+6+6+8 h$ & $29.61 \pm 0.03$ & A & $13.42 \pm 1.39$ & $\mathrm{AB}$ & $43.03 \pm 1.41$ & A & $68.80 \pm 2.20$ & A \\
\hline $4+4+4+4+4+4 h$ & $29.95^{\mathrm{a}} \pm 0.35$ & A & $11.69 \pm 0.00$ & A & $41.64 \pm 0.35$ & A & $71.93 \pm 0.23$ & A \\
\hline \multicolumn{9}{|l|}{ Single-stage } \\
\hline 12 h (optimum) & $27.87 \pm 3.76$ & A & $10.62 \pm 1.63$ & A & $38.49 \pm 2.13$ & A & $72.4 \pm 5.76$ & A \\
\hline $24 \mathrm{~h}$ & $25.07 \pm 4.94$ & A & $17.12 \pm 1.95$ & $\mathrm{~B}$ & $42.19 \pm 2.99$ & A & $59.4 \pm 7.52$ & A \\
\hline
\end{tabular}




\subsection{Stimulation of the growth of probiotic bacteria on BPP hydrolysate}

Two probiotic strains, Lactobacillus gasseri and Lactobacillus plantarum, were used in order to evaluate their capacity to consume the produced cello-OS. Their cultivation on pure glucose or cellobiose demonstrated that they were capable to efficiently use those carbon sources [12]. Growth rate was monitored by the OD at $600 \mathrm{~nm}$ and glucose and cellobiose consumption (Fig. 4). The increase observed in the OD and the consumption of the cellobiose content showed that both strains were able to use the hydrolysate.

$L$. plantarum exhibited a faster growth $\left(\mu=0.30 \mathrm{~h}^{-1}\right)$ and needed $31 \mathrm{~h}$ of incubation to consume practically all the carbohydrates, comparing with the $72 \mathrm{~h}$ needed in the case of $L$. gasseri $\left(\mu=0.07 \mathrm{~h}^{-1}\right)$. The only metabolite detected for both strains was lactic acid; the production of any shortchain fatty acid (acetic, propionic, or butyric acid) was not detected. The amount of lactic acid (Table 3) measured for

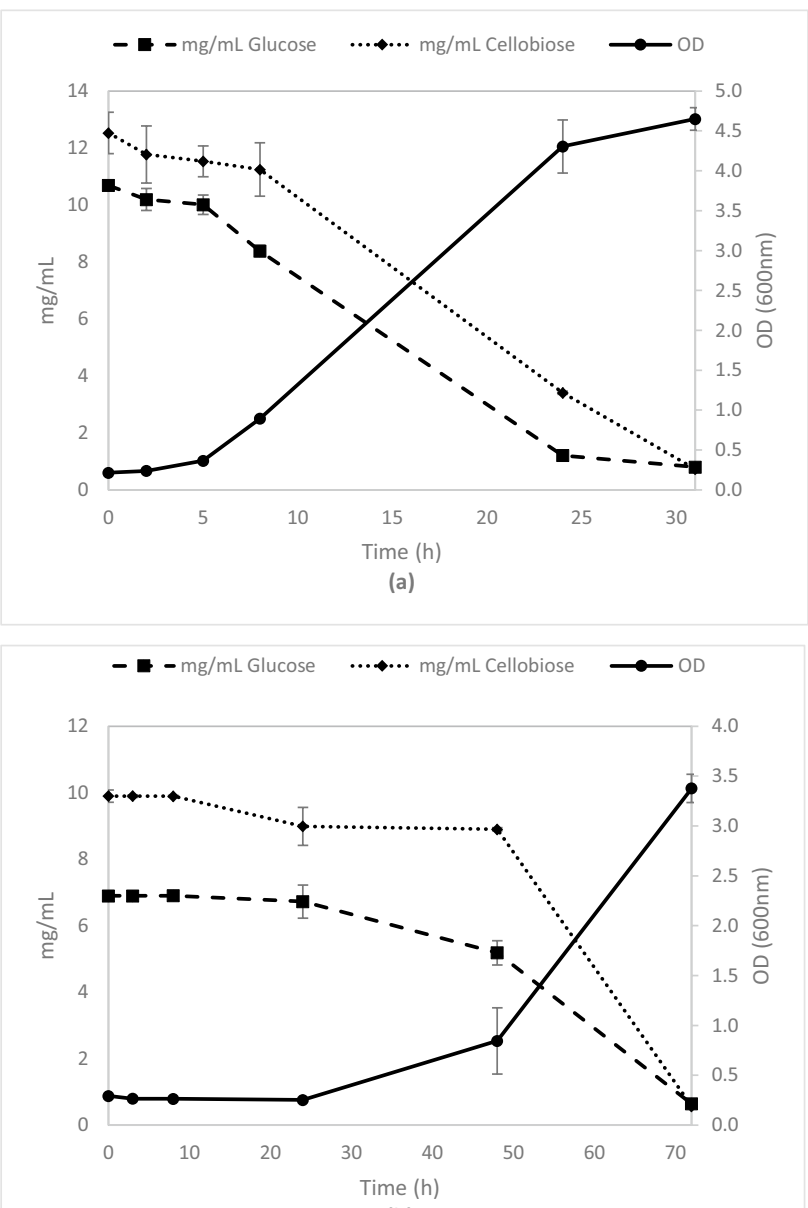

(b)

Fig. 4 Growth curve (OD600 nm) and carbohydrate consumption (glucose and cellobiose) of L. plantarum (a) and L. gasseri (b) grown on culture media supplemented with BPP hydrolysates
Table 3 Fermentation metabolites $(\mathrm{mg} / \mathrm{mL})$ of Lactobacilli strains grown on culture media supplemented with BPP hydrolysate

\begin{tabular}{lrrrrr}
\hline$(\mathrm{mg} / \mathrm{mL})$ & \multicolumn{2}{l}{ L. plantarum } & & \multicolumn{2}{l}{ L. gasseri } \\
\cline { 2 - 3 } \cline { 5 - 6 } & \multicolumn{1}{l}{$0 \mathrm{~h}$} & \multicolumn{1}{l}{$31 \mathrm{~h}$} & & $0 \mathrm{~h}$ & \multicolumn{1}{l}{$72 \mathrm{~h}$} \\
\hline Glucose & $10.17 \pm 0.09$ & $0.00 \pm 0.00$ & & $5.97 \pm 0.15$ & $0.00 \pm 0.00$ \\
Cellobiose & $11.73 \pm 0.73$ & $0.00 \pm 0.00$ & & $8.89 \pm 0.18$ & $0.00 \pm 0.00$ \\
Lactic acid & $0.00 \pm 0.00$ & $34.10 \pm 1.40$ & & $0.00 \pm 0.00$ & $25.02 \pm 0.68$ \\
Acetic acid & $3.63 \pm 0.72$ & $4.86 \pm 0.12$ & & $4.00 \pm 0.01$ & $4.39 \pm 0.11$ \\
$\begin{array}{l}\text { Propionic } \\
\text { acid }\end{array}$ & $0.99 \pm 0.63$ & $1.23 \pm 0.06$ & & $1.04 \pm 0.00$ & $1.39 \pm 0.00$ \\
\hline
\end{tabular}

both bacteria was higher than the amount corresponding to the cellobiose and glucose that was consumed. This can be due to the fact that bacteria can consume other oligosaccharides with higher DP both originated from cellulose and hemicellulose.

\section{Conclusions}

Pre-treatment of BPP is necessary to increase enzymatic hydrolysis yields. Similar global yields and oligosaccharides generation were obtained for P150 and P170, while P150 shows higher cello-oligosaccharides selectivity at lower enzyme dosage. Using a very low dosage (1 FPU/g DB) enabled a greater stability of the cello-oligosaccharides and a very slow glucose production rate. The best yield in cellooligosaccharides was $28 \%$, with a selectivity of $0.72(12 \mathrm{~h}$, $1 \mathrm{FPU} / \mathrm{g} \mathrm{DB})$. On the other hand, the multi-stage strategy did not lead any improvement. The use of endo-glucanase produced high oligosaccharides selectivity but lower yield. Finally obtained cello-oligosaccharides successfully support the in vitro growth of two Lactobacilli probiotic strains.

Supplementary Information The online version contains supplementary material available at https://doi.org/10.1007/s13399-021-02033-4.

Author contribution SD, investigation, methodology, and writing (original draft preparation); ZO, supervision, conceptualization, and writing (reviewing and editing); ANB, supervision and project administration; MDM, funding acquisition and visualization; FC, methodology, resources, and writing (reviewing and editing); LCD, methodology, resources, visualization, and writing (reviewing and editing); LM, methodology and writing (reviewing and editing); EK, investigation; UR, validation and formal analysis; PC, supervision and resources; $\mathrm{MC}$, supervision, conceptualization, visualization, methodology, and writing (reviewing and editing).

Funding Open Access funding provided thanks to the CRUE-CSIC agreement with Springer Nature. The financial support for developing this research work was supplied by Ministry of Education, Culture and Sports of Spain (Grant Ref. FPU15/03138), LIFE BAQUA project (LIFE15 ENV/ES/000157) and ERASMUS + Programme. MED is a research unit funded by National Funds through Foundation 
for Science and Technology (FCT) from Portugal under the Project (UIDB/05183/2020).

\section{Declarations}

Competing interests The authors declare no competing interests.

Open Access This article is licensed under a Creative Commons Attribution 4.0 International License, which permits use, sharing, adaptation, distribution and reproduction in any medium or format, as long as you give appropriate credit to the original author(s) and the source, provide a link to the Creative Commons licence, and indicate if changes were made. The images or other third party material in this article are included in the article's Creative Commons licence, unless indicated otherwise in a credit line to the material. If material is not included in the article's Creative Commons licence and your intended use is not permitted by statutory regulation or exceeds the permitted use, you will need to obtain permission directly from the copyright holder. To view a copy of this licence, visit http://creativecommons.org/licenses/by/4.0/.

\section{References}

1. Souza EL, Liebl GF, Marangoni C et al (2014) Bioethanol from fresh and dried banana plant pseudostem. Chem Eng Trans 38:271-276. https://doi.org/10.3303/CET1438046

2. Saraiva AB, Pacheco E, Visconte LLY, Pereira E (2012) Potentials for utilization of post-fiber extraction waste from tropical fruit production in Brazil-the example of banana pseudo-stem. Int J Environ Bioenergy 4:101-119

3. Díaz S, Ortega Z, Benítez AN et al (2021) Assessment of the effect of autohydrolysis treatment in banana's pseudostem pulp. Waste Manag 119:306-314. https://doi.org/10.1016/j.wasman. 2020.09.034

4. da Silva SS, Chandel AK, Wickramasinghe SR, Domínguez JMG (2012) Fermentative production of value-added products from lignocellulosic biomass. J Biomed Biotechnol 2012:826162. https:// doi.org/10.1155/2012/826162

5. Zheng Y, Yu Y, Lin W et al (2021) Enhancing the enzymatic digestibility of bamboo residues by biphasic phenoxyethanol-acid pretreatment. Bioresour Technol 325:124691. https://doi.org/10. 1016/j.biortech.2021.124691

6. Stickel JJ, Elander RT, Mcmillan JD, Brunecky R (2014) Enzymatic hydrolysis of lignocellulosic biomass. Bioprocessing of Renewable Resources to Commodity Bioproducts. John Wiley \& Sons Inc, Hoboken, pp 77-103

7. Jiao LF, Ke YL, Xiao K et al (2015) Effects of cello-oligosaccharide on intestinal microbiota and epithelial barrier function of weanling pigs. J Anim Sci 93:1157. https://doi.org/10.2527/jas. 2014-8248

8. Chu Q, Li X, Xu Y et al (2014) Functional cello-oligosaccharides production from the corncob residues of xylo-oligosaccharides manufacture. Process Biochem 49:1217-1222. https://doi.org/10. 1016/J.PROCBIO.2014.05.007

9. Pan L, Farouk MH, Qin G, et al (2018) The influences of soybean agglutinin and functional oligosaccharides on the intestinal tract of monogastric animals. Int J Mol Sci 19: https://doi.org/10.3390/ ijms19020554

10. Barbosa FC, Kendrick E, Brenelli LB et al (2020) Optimization of cello-oligosaccharides production by enzymatic hydrolysis of hydrothermally pretreated sugarcane straw using cellulolytic and oxidative enzymes. Biomass Bioenerg 141:105697. https://doi. org/10.1016/j.biombioe.2020.105697

11. Karnaouri A, Topakas E, Matsakas L et al (2018) Fine-tuned enzymatic hydrolysis of organosolv pretreated forest materials for the efficient production of cellobiose. Front Chem 6:128. https:// doi.org/10.3389/fchem.2018.00128

12. Karnaouri A, Matsakas L, Krikigianni E, et al (2019) Valorization of waste forest biomass toward the production of cello-oligosaccharides with potential prebiotic activity by utilizing customized enzyme cocktails. Biotechnol Biofuels 12: https://doi.org/10. 1186/s13068-019-1628-z

13. Karnaouri A, Matsakas L, Bühler S, et al (2019) Tailoring celluclast ${ }^{\circledR}$ cocktail's performance towards the production of prebiotic cello-oligosaccharides from waste forest biomass. Catalysts 9: https://doi.org/10.3390/catal9110897

14. de Souza EL, Sellin N, Marangoni C, Souza O (2017) The influence of different strategies for the saccharification of the banana plant pseudostem and the detoxification of concentrated broth on bioethanol production. Appl Biochem Biotechnol 183:943-965. https://doi.org/10.1007/s12010-017-2475-7

15. Low JC, Halis R, Shah UKM et al (2015) Enhancing enzymatic digestibility of alkaline pretreated banana pseudostem for sugar production. BioResources 10:1213-1223

16. Thakur S, Shrivastava B, Ingale S et al (2013) Degradation and selective ligninolysis of wheat straw and banana stem for an efficient bioethanol production using fungal and chemical pretreatment. 3 Biotech 3:365-372

17. Santa-Maria M, Ruiz-Colorado AA, Cruz G, Jeoh T (2013) Assessing the feasibility of biofuel production from lignocellulosic banana waste in rural agricultural communities in Peru and Colombia. Bioenergy Res 6:1000-1011. https://doi.org/10.1007/ s12155-013-9333-4

18. Kamdem I, Jacquet N, Tiappi FM et al (2015) Comparative biochemical analysis after steam pretreatment of lignocellulosic agricultural waste biomass from Williams Cavendish banana plant (Triploid Musa AAA group). Waste Manag Res 33:1022-1032. https://doi.org/10.1177/0734242X15597998

19. Guerrero AB, Ballesteros I, Ballesteros M (2017) Optimal conditions of acid-catalysed steam explosion pretreatment of banana lignocellulosic biomass for fermentable sugar production. J Chem Technol Biotechnol 92:2351-2359. https://doi.org/10.1002/jctb. 5239

20. Ghose TK (1987) Measurement of cellulase activities. Pure Appl Chem 59:257-268. https://doi.org/10.1351/pac198759020257

21. Sun Y, Cheng J (2002) Hydrolysis of lignocellulosic materials for ethanol production: a review. Bioresour Technol 83:1-11. https:// doi.org/10.1016/S0960-8524(01)00212-7

22. Gregg DJ, Saddler JN (2000) Factors affecting cellulose hydrolysis and the potential of enzyme recycle to enhance the efficiency of an integrated wood to ethanol process. Biotechnol Bioeng 51:375383. https://doi.org/10.1002/(SICI)1097-0290(19960820)51:4\% 3c375::AID-BIT1\%3e3.0.CO;2-F

23. Lin W, Yang J, Zheng Y et al (2021) Understanding the effects of different residual lignin fractions in acid-pretreated bamboo residues on its enzymatic digestibility. Biotechnol Biofuels 14:143. https://doi.org/10.1186/s13068-021-01994-y

24. Gabhane J, Prince William SPM, Gadhe A et al (2014) Pretreatment of banana agricultural waste for bio-ethanol production: individual and interactive effects of acid and alkali pretreatments with autoclaving, microwave heating and ultrasonication. Waste Manag 34:498-503. https://doi.org/10.1016/j.wasman.2013.10. 013

25. Ximenes E, Kim Y, Mosier N et al (2010) Inhibition of cellulases by phenols. Enzyme Microb Technol 46:170-176. https://doi.org/ 10.1016/j.enzmictec.2009.11.001 
26. Romero Pulido MI (2003) Hidrólisis ácida y enzimática del residuo de poda de olivo. Universidad de Jaén

27. Ghose TK, Bisaria VS (1979) Studies on the mechanism of enzymatic hydrolysis of cellulosic substances. Biotechnol Bioeng 21:131-146. https://doi.org/10.1002/bit.260210110

28. Beldman G, Rombouts FM, Voragen AGJ, Pilnik W (1984) Application of cellulase and pectinase from fungal origin for the liquefaction and saccharification of biomass. Enzyme Microb Technol 6:503-507. https://doi.org/10.1016/0141-0229(84)90004-8

29. Chittibabu S, Saseetharan MK, Kalaivani MR, Rajesh MP (2014) Optimization of microwave assisted alkali pretreatment and enzymatic hydrolysis of banana pseudostem for bioethanol production. Energy Sources, Part A Recover Util Environ Eff 36:2691-2698. https://doi.org/10.1080/15567036.2011.574193

30. Shimizu FL, Monteiro PQ, Ghiraldi PHC et al (2018) Acid, alkali and peroxide pretreatments increase the cellulose accessibility and glucose yield of banana pseudostem. Ind Crops Prod 115:62-68. https://doi.org/10.1016/j.indcrop.2018.02.024

31. Raghavendran V, Nitsos C, Matsakas L et al (2018) A comparative study of the enzymatic hydrolysis of batch organosolv-pretreated birch and spruce biomass. AMB Express 8:114. https://doi.org/ 10.1186/s13568-018-0643-y
32. Arantes V, Saddler JN (2010) Access to cellulose limits the efficiency of enzymatic hydrolysis: the role of amorphogenesis. Biotechnol Biofuels 3:4. https://doi.org/10.1186/1754-6834-3-4

33. Kuba Y, Kashiwagi Y, Okada G, Sasaki T (1990) Production of cello-oligosaccharides by enzymatic hydrolysis in the presence of activated carbon. Enzyme Microb Technol 12:72-75. https://doi. org/10.1016/0141-0229(90)90183-Q

34. Singh R, Tiwari S, Srivastava M, Shukla A (2014) Microwave assisted alkali pretreatment of rice straw for enhancing enzymatic digestibility. J Energy 2014:1-7. https://doi.org/10.1155/2014/ 483813

35. Yang J, Zhang X, Yong Q, Yu S (2010) Three-stage hydrolysis to enhance enzymatic saccharification of steam-exploded corn stover. Bioresour Technol 101:4930-4935. https://doi.org/10. 1016/j.biortech.2009.09.079

Publisher's note Springer Nature remains neutral with regard to jurisdictional claims in published maps and institutional affiliations. 